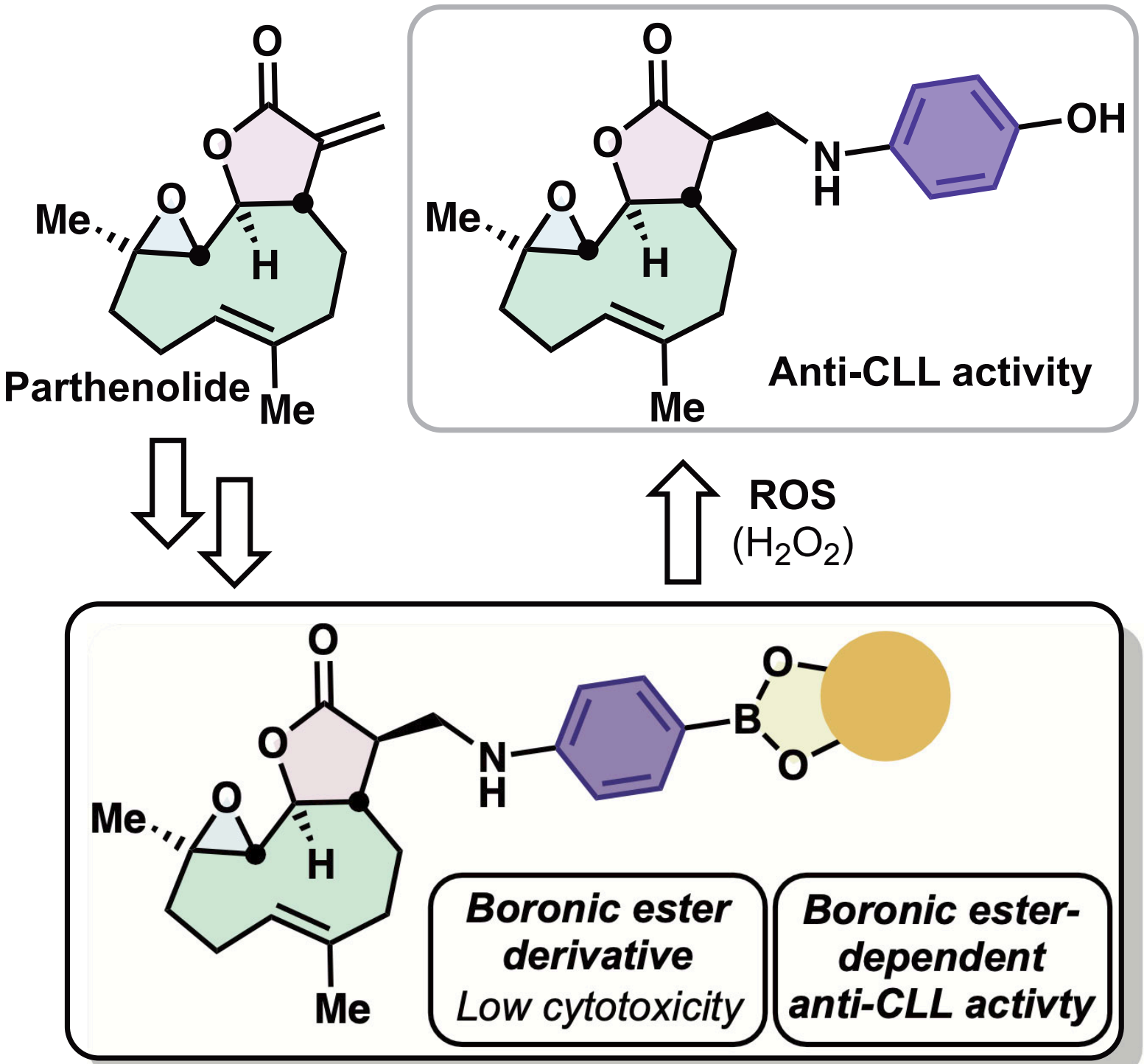




\title{
Boronic ester derivative-dependent activity of parthenolide analogues
}

\author{
Xingjian Li, (a) George T. Williams, ${ }^{(a) \neq}$ Alex S. Quy, ${ }^{(a) \neq}$ Yiming Zhao, ${ }^{(a)}$ Louise Male, ${ }^{(b)}$
} Andrew G. Leach, ${ }^{(c)}$ Eric V. Anslyn, ${ }^{(d)}$ Tatjana Stankovic, $^{(e)}$ Angelo Agathanggelou, ${ }^{*}(e)$ John S. Fossey *(a)

(a) School of Chemistry, University of Birmingham, Edgbaston, Birmingham, West Midlands, B15 2TT, UK

(b) X-Ray Crystallography Facility, School of Chemistry, University of Birmingham, Edgbaston, Birmingham, West Midlands, B15 2 TT, UK;

(d) Division of Pharmacy and Optometry, University of Manchester, Stopford Building, Oxford Road, Manchester M13 9PT, UK

epartment of Chemistry, The University of Texas at Austin, Norman Hackerman Building, 100 E 24th Street Austin Texas, 78712, USA;

e) Institute for Cancer and Genomic Sciences, University of Birmingham, Edgbaston, Birmingham, West Midlands, B15 $2 T T$, UK.

${ }^{\ddagger}$ Contributed equally.

\begin{abstract}
Four parthenolide derived prodrugs, containing different boronic ester moieties, were synthesised, their drug-like properties were calculated and their activity against chronic lymphocytic leukaemia (CLL) MEC1 cells measured. Differences in the clogP, the propensity towards oxidation by hydrogen peroxide, the affinity of the associated diols to a model boronic acid and the biological activity against MEC1 cells were contrasted, and it was found that the propensity for oxidation correlated to biological activity.
\end{abstract}

\section{Introduction}

The most common type of blood cancer in western countries is chronic lymphocytic leukaemia (CLL). ${ }^{1}$ Current treatments for CLL include: conventional chemotherapy in the form of a combination treatment, including fludarabine, cyclophosphamide and rituximab; ${ }^{2}$ targeted cancer drugs, (i.e. ibrutinib or idelalisib); or radiotherapy. ${ }^{3}$ These treatments are non-curative, and suffer poor efficacy against resistant cancer cells. ${ }^{4}$ Furthermore, genome instabilities may render targeted drugs ineffective. ${ }^{5}$ The current chemotherapeutic regimen displays severe side-effects, limiting its use in older patients, or those with other health conditions. ${ }^{6}$ As the median age of CLL diagnosis is 70 , there remains an unmet clinical need for the development of chemotherapeutics with lower cytotoxicity, enabling treatment for this patient group. ${ }^{7}$

A prodrug is a biologically inactive compound which can be converted to an active drug through application of a chemical or biochemical stimulus, often related to metabolism. ${ }^{8}$ This strategy can be used to improve the bioavailability of certain drugs, increase lipophilicity or to help decrease the cytotoxicity of the administered drug. ${ }^{9}$ A variety of activating stimuli can be used including enzymes, ${ }^{10} \mathrm{pH}^{11}$ and reactive oxygen species (ROS). 
The misregulation of ROS in cancer cells leads to an increased intracellular or tumour concentration of hydrogen peroxide in cancer cells, ${ }^{12}$ making hydrogen peroxide an attractive target for prodrug activation or diagnostic development. ${ }^{13}$

Boronic acids can undergo condensation reactions with certain 1,2- and 1,3-diols, yielding cyclic boronic esters. ${ }^{14}$ Both of these species oxidise in the presence of ROS and reactive nitrogen species (RNS), with oxidative cleavage of the carbon-boron bond to yield the corresponding phenols and boronates.

Boronic acids and esters have thus been utilised as hydrogen peroxide sensitive pro-moieties in anticancer prodrugs, ${ }^{15}$ as triggers for molecular chemosensors ${ }^{16}$ and drug-delivery systems. ${ }^{17}$ At present, one boronic acid-containing drug is approved for use. Bortezomib 1, (Figure 1) is a proteasome inhibitor used in the treatment of cancers including multiple myeloma. ${ }^{18} \mathrm{An}$ elegant example of boronic acids or esters used as prodrug triggers was reported by Xue and coworkers. ${ }^{15 a}$ Compound $\mathbf{2}$ was designed as a 5-fluorouracil derivative incorporating a boronic acid bound via a self-immolative linker, showing enhanced tumour selectivity compared to 5fluorouracil, (Figure 1). ${ }^{15 a}$ Chen et al. employed ROS-triggered boronic acid or ester cleavage to deliver phenolic nitrogen mustards from boron-containing prodrugs (exemplified by 3, Figure 1). The boronic ester reduces the electron density around the nitrogen atom, preventing it from forming the active cyclic form of the nitrogen mustard, an aziridinium ring, inhibiting its biological activity. As $\mathbf{3}$ is converted, by action of ROS, into the corresponding phenol, the nitrogen becomes more nucleophilic and can readily form an aziridinium species becoming toxic to cells. The series of compounds studied by Chen et al. displayed excellent selectivity towards CLL cells versus normal lymphocytes. ${ }^{15 b}$ 


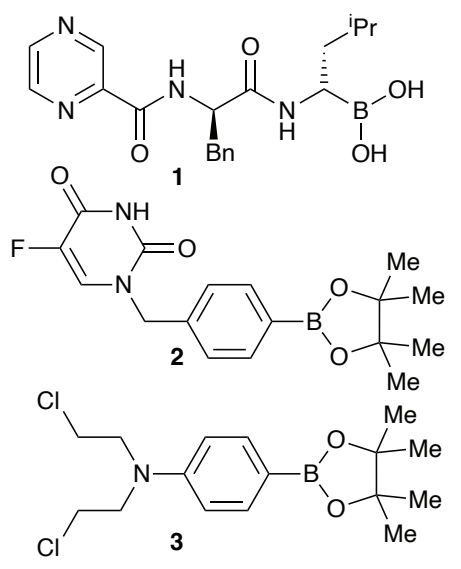

Figure 1. The structure of the boronic acid-containing anticancer drug bortezomib (1) ${ }^{19}$ a boronic ester 5 -fluorouracilderived prodrug (2), Xue and co-workers, ${ }^{15 a}$ and a boronic ester-containing masked nitrogen-mustard DNA crosslinker (3). ${ }^{15 b}$

In the case of both $\mathbf{2}$ and 3, it was observed that under aqueous conditions the boronic esters within these molecules would hydrolyse into the corresponding boronic acid. The equilibria between boronic acids and diols (Scheme 1) and their complex, $\mathrm{pH}$ dependent, kinetics of hydrolysis lead us to hypothesise that the diol constituent used may alter the biological activity of boronic ester containing prodrugs. ${ }^{2 \theta}$

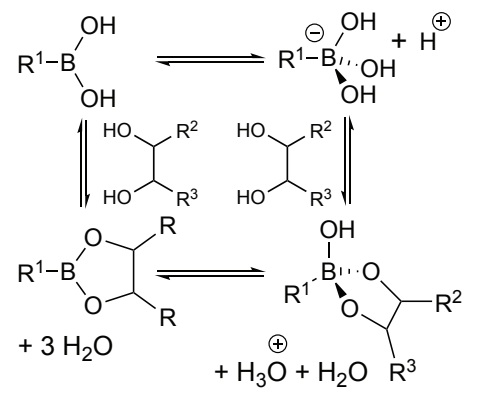

Scheme 1. Equilibria between boronic acids and diols forming boronic esters in aqueous media.

Parthenolide (PTL) (Figure 2, 4), is a bioactive natural product that can be extracted from the plant feverfew (Tanacetum parthenium), ${ }^{21}$ and has shown activity against a range of cancer types including breast, ${ }^{9 a}$ gastric ${ }^{9 b}$ and bladder. ${ }^{9 c}$ Crucially, PTL (4) has also been shown to be effective against leukaemia cells in vitro including CLL. ${ }^{22}$ Unfortunately, PTL (4) displays poor drug-like properties, namely its low aqueous solubility $(\theta .17 \mu \mathrm{M} / \mathrm{mL}$ in serum $),{ }^{23}$ which precludes its use as an orally administered therapy. ${ }^{22 b,} 24$ Previously published research by co-authors of this report outlines the synthesis of aniline derivatives of $\mathbf{4}$, producing a range of compounds active against CLL including 5, Figure 2. Parthenolide derivatives have been shown to act through alkylation of Cys38 on NF-kB, inhibiting DNA binding, ${ }^{25}$ and through the depletion of glutathione. By reducing 
the levels of glutathione, a known antioxidant, ${ }^{26}$ PTL derivatives increase intracellular ROS to concentrations fatal to the cells. As such PTL (4) and its derivatives are considered pro-oxidants, as previously demonstrated by co-authors of this report. ${ }^{27}$ This makes them an attractive scaffold from which to develop boronic ester-based ROS-triggered prodrugs, as their activation is hypothesised to cause a subsequent intracellular cascade of oxidation.

Compound $\mathbf{5}$ was selected as a model platform of a bioactive compound (previously been shown by some co-authors of this report to display activity towards CLL cells) that could be revealed upon the action of ROS on a corresponding boronic ester. Boronic ester-containing derivatives of PTL (4) 6a-d, predicted to oxidise to $\mathbf{5}$, Scheme 2, were chosen for this study. Herein, the synthesis, physicochemical and biological evaluation of these four boronic esters as potential prodrugs that contain boronic ester motifs is described. The boronic esters present in $\mathbf{6 a} \mathbf{a} \mathbf{d}$ were chosen due to the difference in affinity of their corresponding diols (a-c) towards a model boronic acid (see Table 2 , later), the availability of materials to synthesise them, the tractability of their synthesis and their stereochemical features $(\mathbf{d})$. 


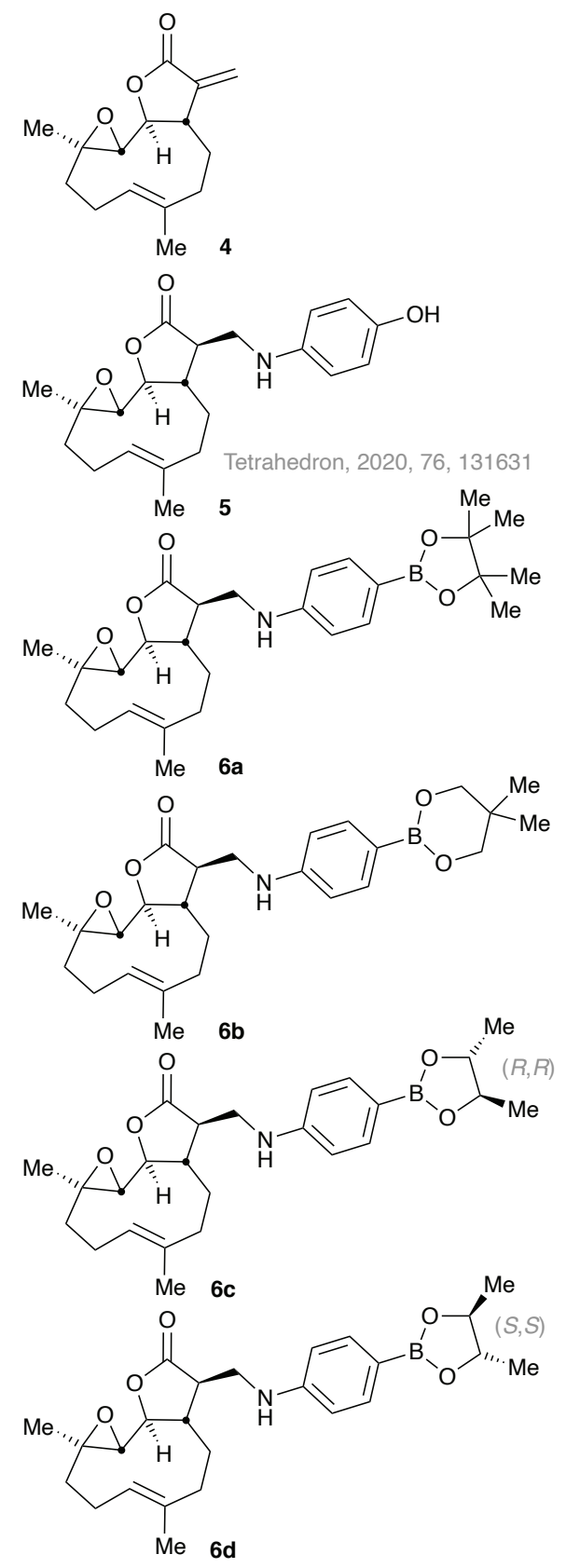

Figure 2. Natural product parthenolide (PTL) 4, aminophenol derivative $5,{ }^{24}$ and PTL-boronic ester derivatives containing: Pinacol esters (6a); neopentyl glycol esters (6b); and trans-2,3 butane diol esters, (R,R 6c) or (S,S $\mathbf{6 d}$ ). 


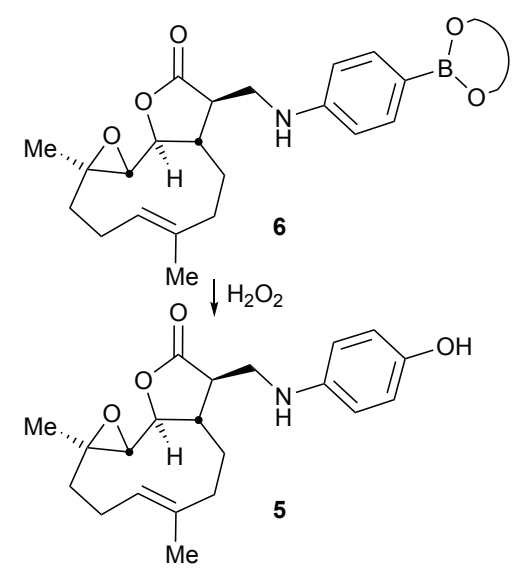

Scheme 2. Proposed ROS-triggered activation of boronic ester containing parthenolide derivatives 6. Hydrogen peroxide-mediated oxidation of generic boronic ester $\mathbf{6}$ giving rise to phenol-containing parthenolide derivative $\mathbf{5}$.

\section{Results and discussion}

\section{Synthesis}

The synthetic path to access boronic esters involved, first extracting parthenolide (4) from the feverfew plant using previously published methods. ${ }^{2 \mathrm{~b}}$ From PTL 4, the phenol containing aniline derivative $\mathbf{5}$ was accessed via a squaric acid-catalysed Michael addition, and subsequent conversion into reactive nonaflate 7. Suzuki-Miyaura borylations, using a palladium-XPhos derived catalyst, were then performed using the relevant diboron compound to yield $\mathbf{6 a - d}$ in 38 to $78 \%$ overall yields. In order to prepare the two stereoisomers of trans-2,3-butanediol, single enantiomer diboronic esters $\mathbf{8 c}$ and $\mathbf{8 d}$ were synthesised in 90 and $86 \%$ isolated yields respectively (see supplementary material for details). 

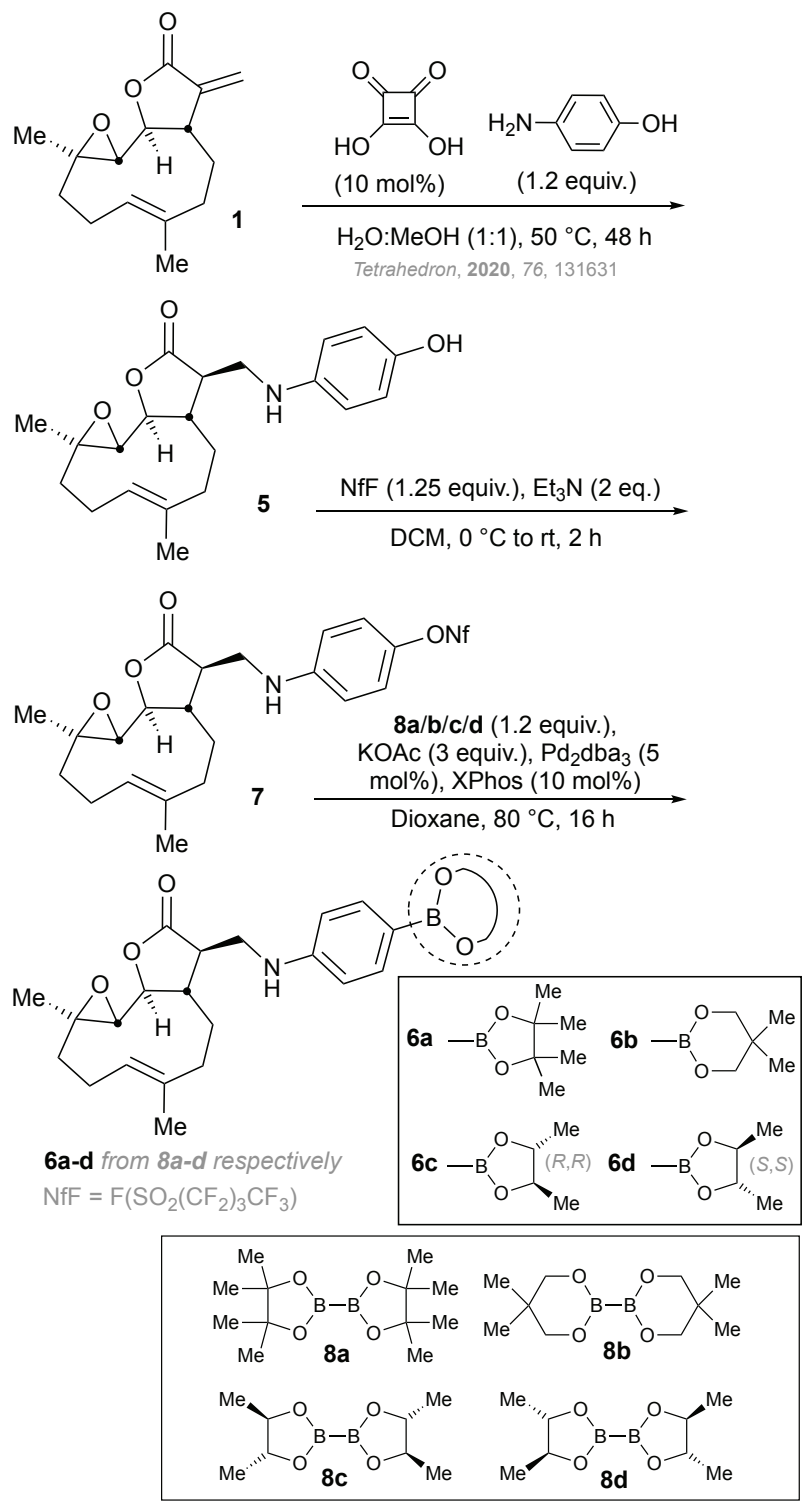

Scheme 3. The synthetic route towards boronic ester containing PTL derivatives 6a-d from nonaflate activated PTL derivative $\mathbf{7}$ and diboron compounds $\mathbf{8 a - d}$.

Crystals suitable for single crystal X-ray diffraction (XRD) structure determination were obtained from compounds $\mathbf{6 c}$ and $\mathbf{6 d}$ (Figure 1, for details see supplementary material). Both $\mathbf{6 c}$ and $\mathbf{6 d}$ display $\mathrm{NH} \cdots \mathrm{O}=\mathrm{C}$ distances indicative of $\mathrm{H}$-bonding 2.5 and $2.3 \AA$ respectively. The relative stereochemistries of diastereomeric $\mathbf{6 c}$ and $\mathbf{6 d}$ are consistent with the absolute stereochemistry of starting materials deployed in their synthesis. 


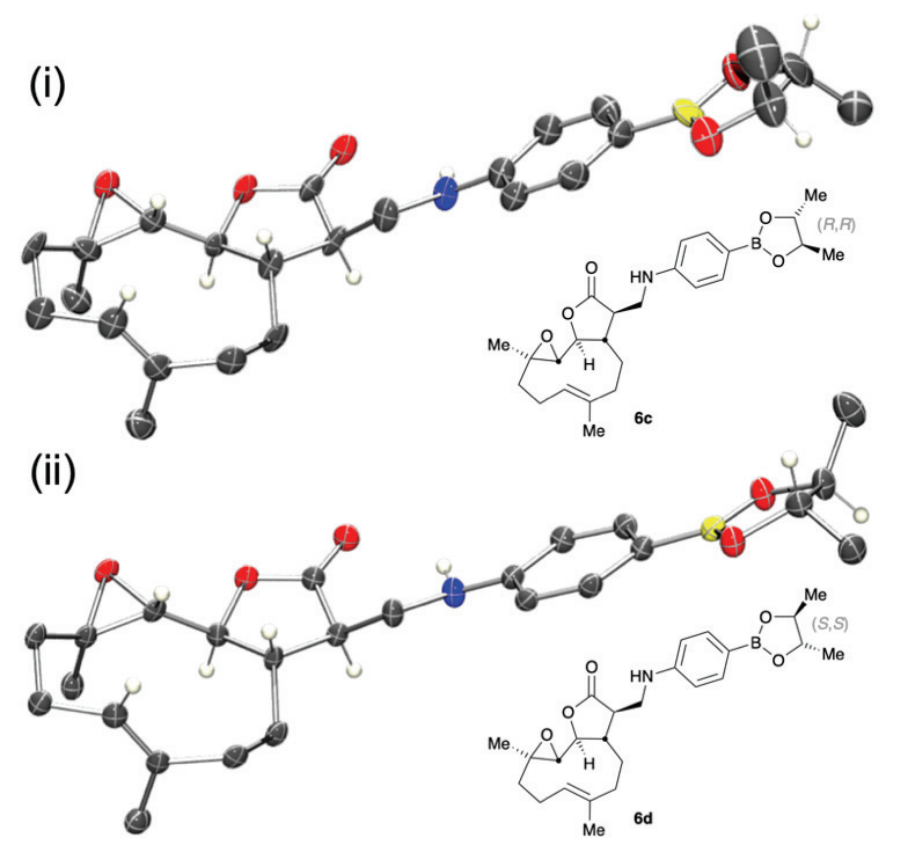

Figure 3. Single crystal X-ray crystal structure of (i) $\mathbf{6 c}$ and (ii) $\mathbf{6} \boldsymbol{d}$. For further detail see supplementary material.

\section{Calculated physiochemical properties}

The molecular weight, fraction of $\mathrm{sp}^{3}$ and clogP were compared for $\mathbf{6 a - d}$ (Table 1); the calculated properties of diastereoisomers $\mathbf{6} \mathbf{c}$ and $\mathbf{6} \mathbf{d}$ were found to be the same. Molecular weights are under $500 \mathrm{Da}$ for each of $\mathbf{6 a - d}{ }^{28}$ Since compounds $\mathbf{6 a - d}$ differ only in the alkyl ester part, the fraction of $\mathrm{sp}^{3}\left(\mathrm{Fsp}^{3}\right){ }^{29}$ follows molecular weight $(\mathbf{0 . 6 5}, \mathbf{0 . 6 4}$ and $\mathbf{0 . 6 2}$ for $\mathbf{6 a}, \mathbf{6 b}, \mathbf{6 c} / \mathbf{d}$, respectively). The lipophilicity of a compound impacts its ability to cross cell membranes and other biological barriers. ${ }^{28 b}$ By changing the alkyl ester part across $\mathbf{6 a}, \mathbf{6 b}, \mathbf{6 c} / \mathbf{d}$ the calculated $\log \mathrm{P}(\mathrm{clog} P$ ) values confirm lipophilicity may be modulated by changing the boronic ester moiety within the molecule (clogP 5.27, 4.57 and 4.44 for $\mathbf{6 a}, \mathbf{6 b}$ and $\mathbf{6 c - d}$, respectively, Table 1, Entry 3-6). ${ }^{30}$ See supplementary material for clogP using alternate predictive models. 
Table 1. Calculated physiochemical properties and activity against MEC1 CLL cells and normal healthy PBMCs for 4, 5 and 6a-d.

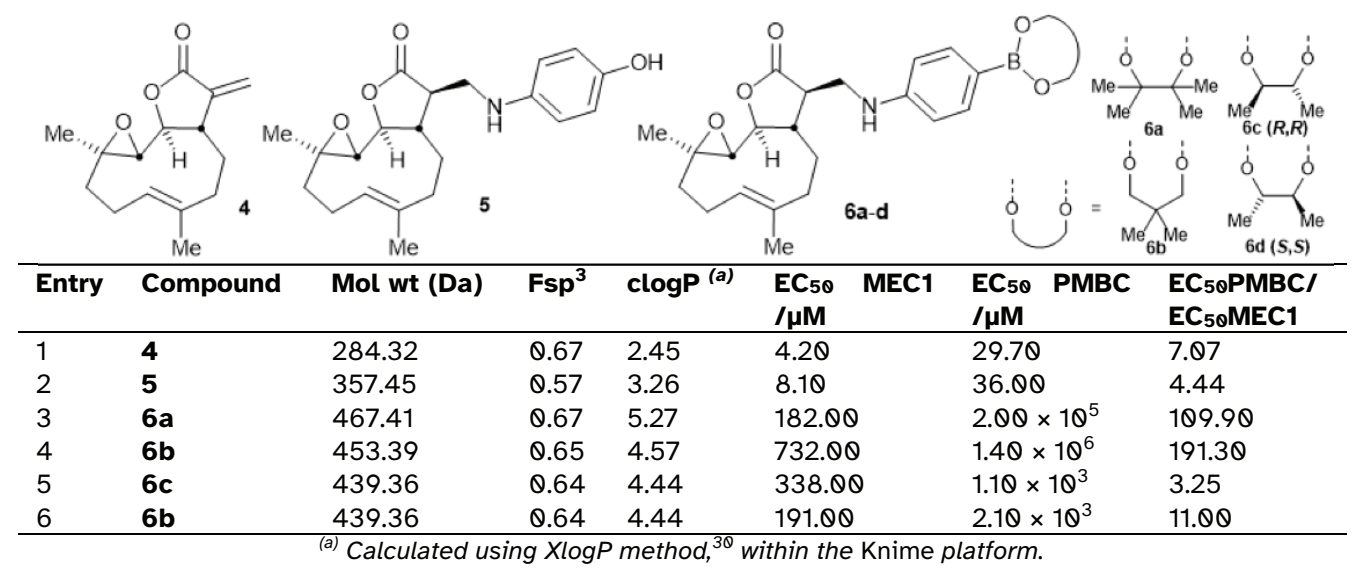

\section{Biological evaluation}

Activity of parthenolide derivatives 6a-d against MEC1 CLL cells was determined using an alamarBlue ${ }^{\circledR}$ (ThermoFisher Scientific) and benchmarked against parthenolide (4) and phenolic parthenolide derivative 5 (Table 1). ${ }^{31}$ The $\mathrm{EC}_{50}$ gives an indication of the efficacy of these compounds at treating this cancer cell line in vitro. Compound 6a-d exhibited very similar cytotoxicity towards the CLL cells, with $\mathrm{EC}_{58}$ values of 182, 732, 338 and $191 \mu \mathrm{M}$ (Table 1, Entry 36). To measure the effect of changing the ester on the ability of these compounds to differentiate between healthy normal human cells and cancer cells, the same assay was performed on normal peripheral blood mononuclear cells (PBMC) (Figure 4b). The $E_{50}$ values obtained in these experiments displayed greater variation than that of the cancer cells; compounds $6 \mathbf{6}$-d gave values of $2.8 \theta \times 10^{5}, 1.4 \theta \times 1 \theta^{6}, 1.10 \times 1 \theta^{3}$ and $2.10 \times 1 \theta^{3} \mu \mathrm{M}$ (Table 1, Entry 3-6). That the EC 50 values calculated against healthy cells is so much higher indicates that these compounds have the potential to act as prodrugs. The ratio between the two $\mathrm{EC}_{50}$ values was calculated (EC $\left.{ }_{58} \mathrm{PBMC} / \mathrm{EC}_{50} \mathrm{MEC} 1\right)$, to compare the differences in activity of each compound between the two cell lines. This yielded values for $\mathbf{4 , 5}$ and $\mathbf{6 a - d}$ of 7.87, 4.44 189.9, 191.3, 3.25 and 11.8 respectively (Table 1). This indicates that compounds $\mathbf{6 a}$ and $\mathbf{6} \mathbf{b}$ display greater selectivity towards CLL cells compared to PBMCs whilst $\mathbf{4 , 5 , 6 c}$ and $\mathbf{6} \mathbf{d}$ show lower specificity; the high $\mathrm{EC}_{50}$ values calculated for $\mathbf{6 a}$ and $\mathbf{6 b}$ are tentatively hypothesised to be a due to the intracellular ROS concentration being insufficient to activate the prodrug over the timescale that this experiment was measured. To rationalise these observations experiments were performed to observe the oxidation of model boronic esters containing these ester substituents. 


\section{Oxidation studies}

The oxidation studies were performed using model compounds 9a-e, Table 2. Keeping the aryl substituent the same so as to avoid affecting the oxidation rate, ${ }^{32}$ the different boronic esters were exposed to hydrogen peroxide (1.2 equiv.) and the conversion into the corresponding phenol was monitored by proton NMR spectroscopy (Figures S7-17); the time taken to achieve $50 \%$ conversion from boronic ester into the phenol is given in Table 2. The equivalent free boronic acid 10 was also investigated (Table 2, entry 5). It is hypothesised that the oxidation rates of compounds 9a-d and $\mathbf{1 0}$ would differ, however in aqueous solutions boronic esters exist as an equilibrium between the boronic ester and the free acid plus the diol. To ensure that this experiment was not measuring the equilibrium hydrolysis rate, an affinity assay using phenyl boronic acid and alizarin red S was performed, ${ }^{14,33}$ (Figure S1-3, Table S1), yielding a ranking order of the different diol affinities towards boronic acids. $50 \%$ of 9 a oxidised into 11 in ten minutes, and pinacol displayed a relative affinity to phenyl boronic acid of 12.1 (Table 2, Entry 1). 9 b oxidised more slowly than 9a, taking 27 minutes to reach $50 \%$ conversion into $\mathbf{1 1}$ (Table 2, Entry 2). The relative affinity value for neopentyl glycol to phenyl boronic acid was also lower than that of pinacol, with a value of $\mathbf{\theta} .38$, (Table 2. Entry 2). As expected, $\mathbf{9 c}$ and $\mathbf{9 d}$ showed identical oxidation rates within the experimental error; these were the fastest to oxidise, yielding a $58 \%$ conversion into 11 in five minutes (Table 2, entries 3 and 4). The relative affinity values of $R, R$ - and S,S-2,3-butanediol to phenylboronic acid are also identical at 8.57 (Table 2, entries 3 and 4). Under the experimental conditions, boronic acid 10 completed a 50\% conversion into 11 in 22 minutes (Table 2, entry 5). That compound $\mathbf{9 b}$ displays a slower oxidation than compound $\mathbf{1 0}$ whilst $\mathbf{9 a}, \mathbf{9 c}$ and $\mathbf{9 d}$ are faster indicates that the oxidation reaction is at least partially independent of the hydrolysis rate. The independence of the oxidation rate to the hydrolysis is further confirmed by the ARS assay, which gives a ranking order for the diol-boronic acid affinity of $12 a>12 c=12 d>12 b$, whereas the propensity for oxidation of the corresponding boronic esters displays a different order of $12 \mathrm{c}=$ $12 \mathrm{~d}>12 \mathrm{a}>12 \mathrm{~b}$. To the best of the authors' knowledge this is the first example of using the diol component of a boronic ester to adjust its stability or reactivity towards ROS. Of the properties calculated or experimentally determined for $\mathbf{6 a}-\mathbf{d}$, there is a correlation between the propensity for oxidation, the clogP and the biological effect against CLL cells in vitro Table 1, however, these do not correlate to the relative affinity values of the diols to phenyl boronic acid. 
Table 2. Time taken for $\mathbf{9 a - d}$ or $\mathbf{1 0}(0.047 \mathrm{mmol})$ to reach $5 \otimes \%$ conversion to phenol $\mathbf{1 1}$ upon reaction with hydrogen peroxide (1.2 equiv.), and corresponding diol (12a-d) relative affinities for phenyl boronic acid.

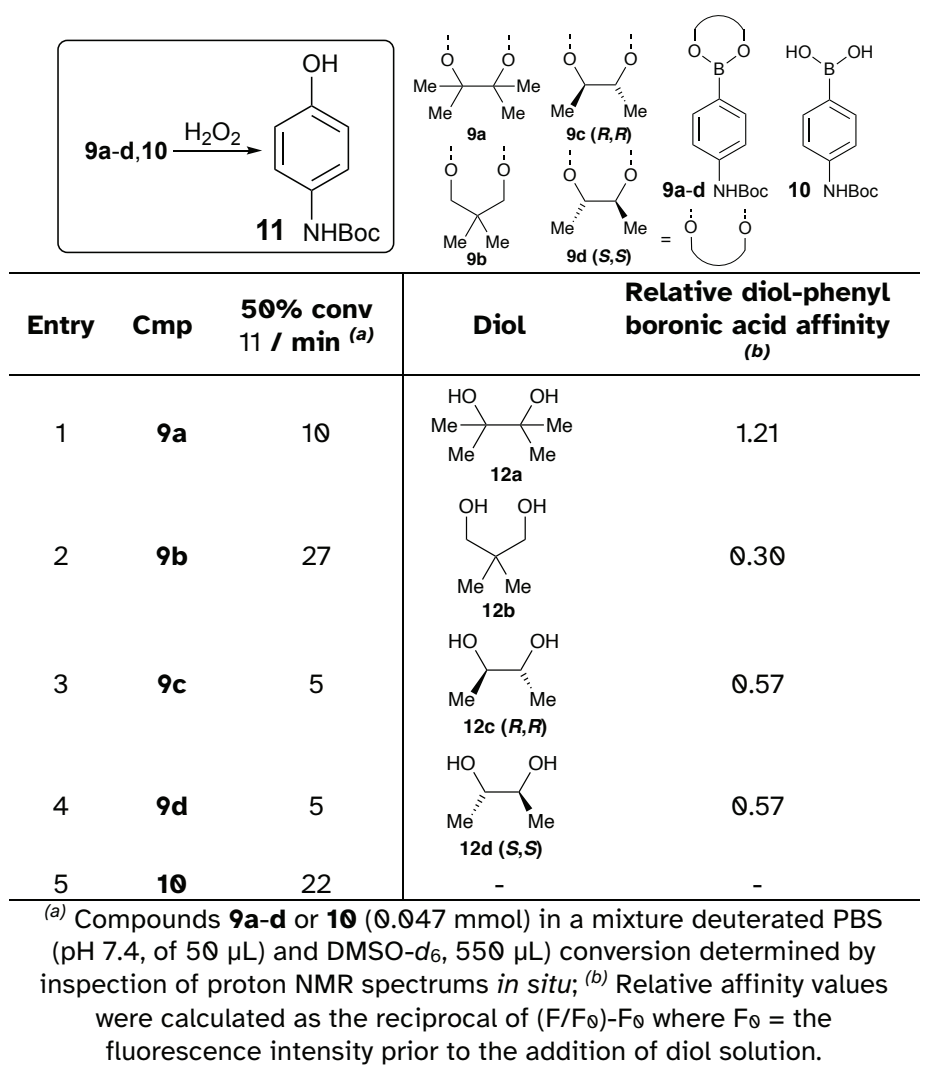

\section{Conclusions}

Four boronic ester containing PTL derivatives were successfully synthesised, and their physicochemical drug-like properties were calculated using the ionic logP algorithm via the CDD Vault platform. It was noted that the chirality of the two trans-2,3-butanediol boronic esters, 6c and $\mathbf{6 d}$, did not affect any of their calculated or measured properties. The in vitro biological activity towards MEC1 CLL and normal PBMC cells was then determined for $\mathbf{6 a - d . ~ W h i l s t ~ e a c h ~ o f ~ t h e ~}$ compounds displayed similar activity towards CLL cells their activity towards healthy cells differed. Further investigation revealed that changing the alkyl constituent of the ester also adjusted the reactivity of the ester towards oxidation by hydrogen peroxide. The increasing sensitivity of the boronic ester towards oxidation correlates with increased biological activity, which is tentatively hypothesised to be due to the increased intracellular oxidation to activate the drug. None of these three properties showed a correlation with the affinity of the corresponding diols to boronic acids, indicating that the trends observed are likely to be independent of the hydrolysis propensity of the boronic esters. 
Being able to tailor boronic esters towards either stability or sensitivity to ROS, whilst keeping the resulting phenol unaltered, has implications beyond prodrug development. Moderating the triggered oxidation rate of boronic acids under physiological conditions could see great application in fields such as sensing or drug delivery in diseases beyond cancer, including

diabetes. ${ }^{34}$ However, further research is needed to elucidate a greater understanding of underlying principles that govern this effect.

\section{Supplementary Information}

Experimental procedures, additional data, supplementary images, additional tables and graphical plots are available in a supporting information file, wherein additional citations are made. ${ }^{35}$ The CIFs for the crystal structures of $\mathbf{6 c}$ and $\mathbf{6 c}$ have been deposited with the CCDC and have been given the deposition numbers CCDC 2117990and CCDC 2117991.

\section{Author contributions}

All authors contributed to the critical assessment of the data, contributed to preparation of and commented upon all aspects of the manuscript. Critical hypotheses of this study pertaining to boronic-derivative use were conceived by AA, JSF, EVA and AGL. JSF, ASQ and GTW wrote most of the text and all authors contributed to critical aspects of the research and decision-making processes presented in this manuscript. AA conceived the central hypothesis of the biological aspects and JSF devised the chemical proposition leading on the chemical aspects. ASQ and XL conducted most of the chemical experimentation, with input from GTW. TS leads the laboratory in which the overarching anti-CLL project is conducted, provided advice, critical input and resources that underpinned the biological aspects.

The authors declare no conflict of interest exists.

\section{Corresponding Author}

*Corresponding authors: For biological aspects AA a.agathanggelou@bham.ac.uk; for chemical aspects JSF j.s.fossey@bham.ac.uk

\section{Acknowledgements}


Co-authors are extremely grateful to Winterbourne House and Gardens (Birmingham U.K.), their staff and their dedicated volunteers, for cultivation of Feverfew from which parthenolide (4) is extracted. Without their unflagging assistance, access to parthenolide would not have been possible. Past and present members of the JSF research group are thanked for collecting feverfew and extracting PTL (4) from it. The University of Birmingham is thanked for support, facilities at the University of Birmingham used to obtain analytical data were supported by the EPSRC (EP/KQ39245/1). CRUK support ongoing research into the use of boronic acids (Pioneer Award 26212). AA and JSF are grateful for the support of internally allocated MRC Confidence in Concepts (14/15) and EPSRC (ISF 2012) pump-priming grants. JSF thanks the EPSRC for past funding (EP/JQ83220/1) that provided enabling apparatus. The laboratory of TS is grateful for the support of Bloodwise (14031) and the CRUK (C20807/A2864). JSF and EVA thank the Royal Society for an International Exchange Grant that facilitated collaborative efforts. EVA thanks the Welch Regents Chair for support (F-0046). AGL acknowledges the University of Manchester for support.

\section{References}

1. K. Patel and J. M. Pagel, J. Hematol. Oncol., 2021, 14.

2. (a) T. Elter, M. Hallek and A. Engert, Expert Opin. Pharmacother., 2086, 7, 1641-1651; (b) M. Simkovic, P. Vodarek, M. Motyckova, D. Ecsiova, P. Rozsivalova, H. Mocikova, P. Stepankova, A. Sykorova, K. Hrochova, F. Vrbacky, D. Belada, P. Zak and L. Smolej, Eur. J. Clin. Invest., 2021, 51, 10.

3. (a) A. R. Mato, B. T. Hill, N. Lamanna, P. M. Barr, C. S. Ujjani, D. M. Brander, C. Howlett, A. P. Skarbnik, B. D. Cheson, C. S. Zent, J. J. Pu, P. Kiselev, K. Foon, J. Lenhart, S. H. Bachow, A. M. Winter, A. L. Cruz, D. F. Claxton, A. Goy, C. Daniel, K. Isaac, K. H. Kennard, C. Timlin, M. Fanning, L. Gashonia, M. Yacur, J. Svoboda, S. J. Schuster and C. Nabhan, Ann. Oncol., 2017, 28, 18501856; (b) B. Pula, B. K. Budziszewska, J. Rybka, L. Gil, E. Subocz, M. Dlugosz-Danecka, D. Zawirska, A. Waszczuk-Gajda, E. Iskierka-Jazdzewska, A. Kopacz, A. Szymczyk, J. Czyz, E. Lech-Maranda, K. Warzocha and K. Jamroziak, Anticancer Res., 2018, 38, 3025-3030; (c) C. Rossier, U. Schick, R. Miralbell, R. O. Mirimanoff, D. C. Weber and M. Ozsahin, Int. J. Radiat. Oncol. Biol. Phys., 2011, 81, E1-E6; (d) D. Decaudin, J. Delic, J. Dumont, G. Tertian, E. Blot, B. Dubray, C. Grandpeix, R. P. De Latour and J. M. Cosset, Leuk. Lymphoma, 2082, 43, 827-829.

4. L. Sedlarikova, A. Petrackova, T. Papajik, P. Turcsanyi and E. Kriegova, Front. Oncol., 2020, 10.

5. S. Y. Yin, R. G. Gambe, J. Sun, A. Z. Martinez, Z. J. Cartun, F. F. D. Regis, Y. Z. Wan, J. Fan, A. N. Brooks, S. E. M. Herman, E. ten Hacken, A. Taylor-Weiner, L. Z. Rassenti, E. M. Ghia, T. J. Kipps, E. A. Obeng, C. L. Cibulskis, D. Neuberg, D. R. Campagna, M. D. Fleming, B. L. Ebert, A. Wiestner, I. Leshchiner, J. A. DeCaprio, G. Getz, R. Reed, R. D. Carrasco, C. J. Wu and L. L. Wang, Cancer Cell, 2019, 35, 283-+.

6. T. J. Hamblin, Nat. Clin. Pract. Oncol., 2809, 6, 130-131.

7. (a) R. L. Siegel, K. D. Miller and A. Jemal, CA Cancer J. Clin., 2020, 70, 7-38; (b) R. L. Siegel, K. D. Miller and A. Jemal, CACancer J. Clin., 2019, 69, 7-34.

8. K. M. Huttunen, H. Raunio and J. Rautio, Pharmacol. Rev., 2011, 63, 750-771. 
(a) A. D'Anneo, D. Carlisi, M. Lauricella, R. Puleio, R. Martinez, S. Di Bella, P. Di Marco, S. Emanuele, R. Di Fiore, A. Guercio, R. Vento and G. Tesoriere, Cell Death Dis., 2013, 4, e891; (b) M. H. Liu, Y. Yang, D. J. Liu, Y. Cao and Y. Li, J. Tradit. Chin. Med., 2020, 40, 908-916; (c) G. Cheng and L. P. Xie, Molecules, 2011, 16, 6758-6768.

10

11.

R. Walther, J. Rautio and A. N. Zelikin, Adv. Drug Deliv. Rev., 2017, 118, 65-77.

Y. Liu, D. Li, X. H. Guo, H. W. Xu, Z. Li, Y. L. Zhang, C. J. Song, R. Fan, X. Tang and Z. Z. Zhang, Int J Nanomed, 2017, 12, 22272242.

T. P. Szatrowski and C. F. Nathan, Cancer Res., 1991, 51, 794-798.

(a) E. O. Hileman, J. S. Liu, M. Albitar, M. J. Keating and P. Huang, Cancer Chemother. Pharmacol., 2084, 53, 209-219; (b) Y. Yu, J. R. Peng, M. Pan, Y. Ming, Y. Li, L. P. Yuan, Q. Y. Liu, R. X. Han, Y. Hao, Y. Yang, D. R. Hu, H. Li and Z. Y. Qian, Small Methods, 2021, 5, 11.

G. Springsteen and B. Wang, Tetrahedron, 2082, 58, 5291-5300.

(a) Y. Ai, O. N. Obianom, M. Kuser, Y. Li, Y. Shu and F. T. Xue, ACS Med. Chem. Lett., 2019, 10, 127-131; (b) W. Chen, K. Balakrishnan, Y. Kuang, Y. Han, M. Fu, V. Gandhi and X. Peng, J. Med. Chem., 2014, 57, 4498-4510.

(a) L. C. Murfin, M. Weber, S. J. Park, W. T. Kim, C. M. Lopez-Alled, C. L. McMullin, F. Pradaux-Caggiano, C. L. Lyall, G. KociokKöhn, J. Wenk, S. D. Bull, J. Yoon, H. M. Kim, T. D. James and S. E. Lewis, J. Am. Chem. Soc., 2019, 141, 19389-19396; (b) G. T. Williams, A. C. Sedgwick, S. Sen, L. Gwynne, J. E. Gardiner, J. T. Brewster, J. R. Hiscock, T. D. James, A. T. A. Jenkins and J. L. Sessler, Chem. Commun., 2020, 56, 5516-5519.

B. L. Patenall, G. T. Williams, L. Gwynne, L. J. Stephens, E. V. Lampard, H. J. Hathaway, N. T. Thet, A. E. Young, M. J. Sutton, R. D. Short, S. D. Bull, T. D. James, A. C. Sedgwick and A. T. A. Jenkins, Chem. Commun., 2019, 55, 15129-15132.

M. V. Mateos and J. F. S. Miguel, Best Pract. Res. Clin. Haematol., 2087, 20, 701-715.

C. T. Supuran, Biorg. Med. Chem., 2016, 24, 4406-4409.

H. L. D. Hayes, R. Wei, M. Assante, K. J. Geogheghan, N. Jin, S. Tomasi, G. Noonan, A. G. Leach and G. C. Lloyd-Jones, J. Am. Chem. Soc., 2821, 143, 14814-14826.

A. M. G. Brown, K. C. Lowe, M. R. Davey and J. B. Power, Plant Sci., 1996, 116, 223-232.

(a) V. Tyagi, H. Alwaseem, K. M. O'Dwyer, J. Ponder, Q. Y. Li, C. T. Jordan and R. Fasan, Biorg. Med. Chem., 2016, 24, 38763886; (b) X. J. Li, D. T. Payne, B. Ampolu, N. Bland, J. T. Brown, M. J. Dutton, C. A. Fitton, A. Gulliver, L. Hale, D. Hamza, G. Jones, R. Lane, A. G. Leach, L. Male, E. G. Merisor, M. J. Morton, A. S. Quy, R. Roberts, R. Scarll, T. Schulz-Utermoehl, T. Stankovic, B. Stevenson, J. S. Fossey and A. Agathanggelou, MedChemComm, 2019, 10, 1379-1390; (c) A. Agathanggelou, V. J. Weston, T. Perry, N. J. Davies, A. Skowronska, D. T. Payne, J. S. Fossey, C. E. Oldreive, W. Wei, G. Pratt, H. Parry, D. Oscier, S. J. Coles, P. S. Hole, R. L. Darley, M. McMahon, J. D. Hayes, P. Moss, G. S. Stewart, A. M. R. Taylor and T. Stankovic, Haematologica, 2015, 100, 1076-1085; (d) A. J. Steele, D. T. Jones, K. Ganeshaguru, V. M. Duke, B. C. Yogashangary, J. M. North, M. W. Lowdell, P. D. Kottaridis, A. B. Mehta, A. G. Prentice, A. V. Hoffbrand and R. G. Wickremasinghe, Leukemia, 2006, 20, 1073-1079.

C. J. Sweeney, S. Mehrotra, M. R. Sadaria, S. Kumar, N. H. Shortle, Y. Roman, C. Sheridan, R. A. Campbell, D. J. Murry, S. Badve and H. Nakshatri, Mol. Cancer Ther., 2005, 4, 1004-1012.

A. S. Quy, X. J. Li, L. Male, T. Stankovic, A. Agathanggelou and J. S. Fossey, Tetrahedron, 2020, 76, 10.

A. J. Garcia-Pineres, V. Castro, G. Mora, T. J. Schmidt, E. Strunck, H. L. Pahl and I. Merfort, J. Biol. Chem., 2001, 276, 3971339720.

(a) M. Valko, D. Leibfritz, J. Moncol, M. T. D. Cronin, M. Mazur and J. Telser, Int. J. Biochem. Cell Biol., 2007, 39, 44-84; (b) Y. L. Sun, D. K. S. Clair, Y. Xu, P. A. Crooks and W. H. S. Clair, Cancer Res., 2010, 70, 2880-2890.

A. Agathanggelou, V. J. Weston, T. Perry, N. J. Davies, A. Skowronska, D. T. Payne, J. S. Fossey, C. E. Oldreive, W. B. Wei, G. Pratt, H. Parry, D. Oscier, S. J. Coles, P. S. Hole, R. L. Darley, M. McMahon, J. D. Hayes, P. Moss, G. S. Stewart, A. M. R. Taylor and T. Stankovic, Haematologica, 2015, 180, 1876-1885. 
28. (a) C. A. Lipinski, F. Lombardo, B. W. Dominy and P. J. Feeney, Adv. Drug Deliv. Rev., 2081, 46, 3-26; (b) A. M. Seddon, D. Casey, R. V. Law, A. Gee, R. H. Templer and O. Ces, Chem. Soc. Rev., 2089, 38, 2509-2519.

29. W. Wei, S. Cherukupalli, L. Jing, X. Liu and P. Zhan, Drug Discov. Today, 2020, 25, 1839-1845.

30. R. X. Wang, Y. Fu and L. H. Lai, J. Chem. Inf. Comput. Sci., 1997, 37, 615-621.

31. (a) M. M. Nociari, A. Shalev, P. Benias and C. Russo, J. Immunol. Methods, 1998, 213, 157-167; (b) G. R. Nakayama, M. C. Caton, M. P. Nova and Z. Parandoosh, J. Immunol. Methods, 1997, 204, 205-208.

32. S. Cao, R. Christiansen and X. H. Peng, Chem. Eur. J., 2013, 19, 9850-9858.

33. W. L. A. Brooks, C. C. Deng and B. S. Sumerlin, ACS Omega, 2018, 3, 17863-17870.

34. (a) G. T. Williams, J. L. Kedge and J. S. Fossey, ACS Sensors, 2821, 6, 1508-1528; (b) Ł. Banach, G. T. Williams and J. S. Fossey, Adv. Ther., 2021, in press, doi: 10.1002/adtp. 202100118.

(a) G. Springsteen and B. H. Wang, Chem. Commun., 2801, DOI: 18.1839/b104895n, 1688-1689; (b) G. M. Sheldrick, Acta Crystallogr. Sect. A, 2088, A64, 112-122; (c) O. V. Dolomanov, L. J. Bourhis, R. J. Gildea, J. A. K. Howard and H. Puschmann, J. Appl. Crystallogr., 2089, 42, 339-341; (d) K. Lawrence, S. E. Flower, G. Kociok-Kohn, C. G. Frost and T. D. James, Analytical Methods, 2012, 4, 2215-2217; (e) CrysAlisPro, 2015, Version 1.171.38.43f, Agilent Technologies; (f) G. M. Sheldrick, Acta Crystallogr. Sect. A, 2015, A71, 3-8; (g) CrysAlisPro, 2020, Version 1.171.40.84a, Agilent Technologies. 